\title{
Optimization of natural gas mixture design by computational method for improving swirl effect to obtain enhancement of SI engine performance: A Review
}

\author{
M. A. Shaikh ${ }^{+*}$ and Aditya H. Shukla ${ }^{\ddagger}$ \\ †Automobile Engineering Department, L. D. College of Engineering, Ahmedabad, Gujarat, India \\ ¥Mechanical Engineering Department, L. D. College of Engineering, Ahmedabad, Gujarat, India \\ Accepted 02 Sept 2016, Available online 05 Sept 2016, Vol.6, No.5 (Oct 2016)
}

\begin{abstract}
CNG is one of the most feasible and accessible option as a replacement of conventional fuels likes Gasoline and Diesel nowadays. But major problem of using it as fuel for automotive purpose is reduced engine performance in terms of power and torque. Out of some parameters that may overcome this deficiency, swirl motions of charge in cylinder is emphasized in this study to enhance the performance of engine and so to negotiate mentioned difficulty. The component that prepares the charge by mixing CNG with air must be the primary source that imparts the swirling motion and so optimization of CNG Mixer design considering various factors is carried out. In majority of studies Computational Fluid Dynamics (CFD) is used to simulate Mixer design. The main objective of this study is to guide how optimum design can be obtained which has highest tendency of producing swirl motion and testing that Mixer experimentally, the performance of engine is recorded. Thus by varying swirl intensity the enhancement in engine performance is obtained. This study is thus helpful to design Mixer and shows path if possibility of further modification in design exists.
\end{abstract}

Keywords: Compressed natural gas, Computational fluid dynamics, Mixer, Swirl and Tumble motion.

\section{Introduction}

It is evident that all conventional reserve of fuel is tending to diminish in near future. So thereis the only way of turning back to alternative fuel is left. CNG serves that purpose and also eco-friendly kind of fuel as it emits lesser pollutant to the environment as compared to gasoline and other conventional fuels.

\section{Compressed Natural Gas}

A gaseous hydrocarbon fuel obtained from underground sources. Natural Gas remains in the gaseous state under the temperature and pressure conditions in service. A mixture of primarily methane $\left(\mathrm{CH}_{4}\right)$ and may also include ethane $\left(\mathrm{C}_{2} \mathrm{H}_{6}\right)$, propane $\left(\mathrm{C}_{3} \mathrm{H}_{8}\right)$, butane $\left(\mathrm{C}_{4} \mathrm{H}_{10}\right)$ and other higher hydrocarbons. It generally also includes some inert gases, such as nitrogen $\left(\mathrm{N}_{2}\right)$ and carbon dioxide $\left(\mathrm{CO}_{2}\right)$ plus minor amounts of trace constituents. Constituents' composition in percentage for $\mathrm{CNG}$ is $70-90 \% \mathrm{CH}_{4}, 10$ $20 \% \mathrm{C}_{2} \mathrm{H}_{6}, 2-8 \% \mathrm{C}_{3} \mathrm{H}_{8}$ and higher $\mathrm{HC}$ up to Butane.

Characteristics: It is colorless, tasteless, odorless and lighter than air. At atmospheric temperature it is in

*Corresponding author: M. A. Shaikh gaseous state and remains in gaseous state for any temperature above minus $161^{\circ} \mathrm{C}$. High ignition temperature and narrowflammability range making it an inherently safe fossil fuel compared to other fuels. Compressed Natural Gas is practically Sulphur free and produces virtually no $\mathrm{SO}_{2}$, emits lower levels of $\mathrm{NO}_{\mathrm{X}}$ and $\mathrm{CO}_{2}$. Compressed Natural Gas (CNG) is attractive for five reasons.

(1) It is the only fuel cheaper than gasoline or diesel.

(2) It has inherently lower air pollution emissions.

(3) It has lower greenhouse gas emissions.

(4) Its use extends petroleum supplies.

(5) There are large quantities of the fuel available.

The difficulties with CNG arise from vehicle range, fuel storage, infrastructure costs and ensuring sufficient supply. When evaluating different alternative fuels one has to take into account many aspects adequacy of fuel supply, process efficiency, ease of transport and safety of storage, Modifications needed in the distribution/refueling network in the vehicle, Fuel compatibility with vehicle engine (power, emissions, ease of use, and durability of engine). Many investigations were carried out in order to use of CNG as an alternative fuel in an engine could be divided into 
three main types according to their fuel usage and they are: Dual Fuel, Bi- Fuel, and Dedicated/Mono Fuel.

Converting SI-Engine to CNG: To run existing SI Engine on CNG fuel some modification is required. Basically conversion kits are available readily in market that contains CNG storage tank, ECU and injectors, reducer, gas filter, fuel selection switch, gas filling valve and solenoid valve to achieve the purpose. The conversion of petrol fuel system into CNG for carbureted engines applies to all auto-cycle with fuel feed system for carburetor. This system consists of a pressure reducer of three stages for reducing pressure of cylinder 200 bars to atmospheric 1 bar allowing the engine to be operated with CNG. There is a switch provided on the dashboard for changeover of fuel from petrol to CNG and vice versa. The LED screen indicates the amount of fuel which is stored in the tank.

Converting CI-Engine to CNG: Diesel to natural gas conversion requires careful engineering on the base engine modifications as well as the control system. The investment required means that these projects only make sense for larger volume fleets. Very basic overview of modifications required for a successful conversion is compression ratio, spark plugs, valves, thermal issues, catalytic converter and engine management system.

Motion of the charge (Fuel + Air) is major factor that controls the combustion and fuel-air mixing process and it also has significant effect on heat transfer. Initial in cylinder flow pattern is set up by intake process. This pattern will later be modified during compression. The flow into the cylinder through the inlet valve or valves (forming a jet) does two things. First, the geometrical configuration of the inlet ports and the valves, and their opening schedule creates organized motions in the cylinder known as Swirl and Tumble. Second, the jet itself is turbulent so resulting in a very high turbulence level during the inlet stroke. It is necessary to be familiar with swirl and tumble motion. Swirl motion is the motion of the charge around the major axis of the cylinder is known as swirl motion whereas tumble motion is the motionof the charge orthogonal to the major axis of the cylinder is known as tumble motion.

Thus for any engine to run on CNG, the properties of air and CNG mixture and flow pattern of charge $(\mathrm{CNG}+\mathrm{Air})$ before entering the combustion chamber is key factor in context of engine performance. This mixture is prepared in the Mixer which the important component of any CNG kit and has direct influence on many factors improving engine performance. Swirl motion of the charge is one of those factors. Optimization of those factors can easily be achieved by improving mixer design.

Under this study various design parameters of mixer is evident and each of those have direct influence on varying pressure and velocity distribution of flow. Tendency of swirl is directly dependent on pressure and velocity distribution. Hence it is very important to have most uniform and optimum distribution and that can be obtained by fluid flow analysis via simulation techniques.

\section{Literature review}

(Semin \& Bakar, 2008) have mentioned certain key benefits and problems that may raise using CNG as fuel in IC-Engines in their review paper A technical review of compressed natural gas as an alternative fuel for internal combustion engines. Major benefits mentioned: (1) Cheaper fuel compared to gasoline and diesel. (2) Low air pollution and low greenhouse emissions. (3) Its use extends petroleum supply and Availability is not major issue. Problems highlighted: (1) Problem related to set point which optimizes both emissions and fuel economy. (2) A/F ratio has to be changed depending upon various operating conditions and fuel properties (Bharadwaj, et al., 2013).

The work of (Bharadwaj et al., 2013) in Study of swirl and tumble motion using CFD basically focuses on the basic definitions and calculations of swirl and tumble co-efficient. CFD simulation of air flow in ICEngine has been carried out to show variation in swirl and tumble ratio with varied crank angle. The conclusion was made that to improve swirl and tumble intensity Kinetic Energy (i.e. Velocity of charge) must be high at inlet valve and thereby requiring the small cross section of inlet valve. Above statement is contradiction in case of high speed engine where for better air flow large cross section area is necessary (Wendy, et al., 2008-Ramadan, 2009)

(Ramadan, 2009) believes that swirl can be generated using following provisions and has presented the same in A study of swirl generation in DI Engines using KIVA-3V. This study forms the basis for swirl generation using following provisions: (1) Effect of conventionaland shrouded valve (2) Effect of port diameter on swirling motion (3) Effect of using one and two intake ports in engine. Effect of above mentioned parameters on the swirl ratio was observed via simulation. This study has concluded that: (1) Using only single and shrouded valve improves the swirl generation. (2) By using reduced port diameter swirl can be improved up to small extent but at the expense of high pumping loss. So approach of reducing port diameter to improve swirl ratio is least acceptable (Poulos, et al., 1983, Abianeh,2009, Kumar,2007).

(Abianeh, 2009) in Investigation of swirling and tumbling flow pattern of spark ignition engine has concentrated on calculations of swirl and tumble ratio. These ratios found were validated by following two methods: (1) Experimental calculation using four cylinder four valve engines (2) Simulation via CFD is performed for validation purpose. For mentioned work three configuration having three different flow patterns is tested. They were: (1) Base line engine (2) Blocking part of intake port using flow control baffle (3) Blocking entire of one of intake valve using flow 
control baffle (from two intake valve). The effect of mentioned three configurations onlean burn capacity and emissions has observed and analyzed (kumar, et al., 2007).

(Kumar, et al, 2007) in Air flow and charge motion study of engine intake port have carried out research work related to measurement of flow coefficient and swirl ratio for basic three kind of valve lift: Low, Medium and High. The required data is recorded by two means: (1) Using

Experimental set up followed by theoretical calculations (2) Using CFD software - Virtual flow bench. Conclusion was made that for low and medium valve lift data recorded by both means validate each other nearly. But for high valve lift large deviation is observed in CFD and experimental data (Kang,1999, Mohiuddin Kyung,2001)

The investigation of (Mohiuddin, 2011) published as research paper Investigation of the swirl effect on engine using designed swirl adapter mainly emphasis on swirl production techniques like: (1) Flow must be discharged tangentially towards the cylinder wall (2) By forcing the flow to rotate around vertical axis of intake valve before entering the cylinder (3) Masking or shrouding of periphery of inlet valve or cylinder head around inlet valve (Takenaka, et al. 1990,Kang, et al. , 1999, Mohiuddin, 2011)

Thesis work done by (Zhang, 1995) on Turbulence swirling combustion of premixed natural gas and air. In which investigation was done on effect of turbulence and swirl intensity on burning rate via experimental and numerical simulation method. Swirl was generated by a rotating disc in combustion chamber with variable intensity. Turbulence intensity was variedby changing the swirl level as well as changing the size of roughness on disc. This research was concluded as the combustion rate of premixed natural gas and air can be significantly affected by swirl. Under the experimental condition of this work, i.e. with stoichiometric natural gas and air mixtures ignited at the centre of the cylindrical combustion chamber with length to diameter ratio 0.5, Reynold's number from 0 to 252000, swirl has both positive and negative effect on combustion rate. So to maximize overall combustion rate there is optimum swirl intensity (Porpatham, 2013, Sita Rama Raju AV,2001)

(Porpatham et al, 2013) have published research paper Effect of swirl on the performance and combustion of a biogas fueled spark ignition engine. Theinfluence of swirl on the performance, emissions and combustion in a constant speed Spark Ignition(SI) engine was studied experimentally. A single cylinder diesel engine was modified to operate as a biogas operated spark ignition engine. Based on the present experimental work to study the effect of swirl to enhance the combustion characteristics of biogas fueled spark ignition engine, the conclusions drawn are: (1) There is an improvement in brake thermal efficiency and power output with increase in swirl level. Increase in brake thermal efficiency is higher at full throttle compared to part throttle with masked valve configuration. (2) There is decrease in $\mathrm{HC}$ level and increase in NO emission with enhanced swirl with full throttle. This is mainly due to the improvement in combustion by way of extension of the lean limit and increase in the combustion rate. (3) There is a reduction in the ignition delay and significant increase in heat release rate with enhanced swirl level.

(Kim,et al. 2007) have published their study as Effect of intake valve swirl on fuel-gas mixing and subsequent combustion in a CAI engine in which a fully three-dimensional model was used to investigate the optimal value for intake valve lift in a CAI engine. Uniform mixing in the engine is a key parameter that affects the auto-ignition reliability and thermal efficiency. The method of intake of the air supply often determines the uniformity (or quality) of the fuel-air mixture. It was concluded that the methods of supplying the intake air, swirling or/and tumbling, often determine the quality or uniformity of mixing. To investigate the effects of swirl on fuel-air mixing and its subsequent combustion for a CAI engine, parametric studies were conducted by using a fully three dimensional model. They also found that high fuel concentration and the auto-ignition spots affected each other and that this effect is especially prominent when the equivalence ratio is low. However, the higher temperature increases the amount of nitric oxide (NO) emission.

Optical study of swirl during combustion in a CI engine with different injection pressures and swirl ratios compared with calculations by (Henrik, et al., 2011) deals with Spray and mixture formation in a compression-ignition engine is of paramount importance in the diesel combustion process. By changing the in-cylinder flow, the emissions and engine efficiency are affected. Optical engine studies were therefore performed on heavy-dutyengine geometry at different fuel injection pressures and inlet airflow characteristics. By applying different inlet port designs and valve seat masking, swirl and tumble were varied. The main conclusions from this study were that the mean swirl numbers, evaluated with the PIV software from combustion pictures around TDC, agreed with CFD based correlations and the low swirl numbers also correlated with the 1Dsimulationprogram. Most of the induced swirl motion survives the compression and combustion, while the induced tumble does not survive to the late combustion phase. This study also shows that the angular velocity at different piston bowl radii deviates from solid body rotation. The angular velocity is higher closer to the center and decreases to be at the lowest value at the outer piston bowl edge. When the injection pressure is increased, the deviation from solid body rotation increases due to spray effects.

Thesis work done by (Kumar, 2012) on Studies on improvement of intake manifold for compressed 
natural gas engine deals with geometrical design of intake manifold which is very important for the good performance of an I.C.Engine. Unequal velocity distribution of intake air at runner's outlets of intake manifold makes it less efficient. The reported work aims to make this unequal distribution of velocity in nearly equal manner with increase of velocity at outlets without any major modification in design of intake manifold. Maruti Wagon-R (petrol version) engine intake manifold is used for experimental testing and To modify the intake manifold first a 3-D model of actual manifold is made in design software (PRO-E) and then validation of design model is done by using commercial CFD software FLUENT. One of the important point that must be kept in mind while designing intake manifold or any other part is that the projection must be as minimum as possible to avoid pressure losses and so better velocity distribution can be achieved.

(Dr. Bakar et al.,2002) have published their study as Design and development of a new CNG (Compressed Natural Gas) engine in which main concentration was given to design the mixer of different kind by varying design parameters like number of holes, input and output angle. To improve swirl intensity swirl device was also adopted with two main variables number of revolution and angle of plane. Conclusion was made that the combination of $60^{\circ}$ of inlet angle and $30^{\circ}$ of outlet angle with 8 holes is proven to increase the engine performance to up to $5 \%$ that made it closer to the gasoline standard engine performance and the swirl-device located at the intake port is verified to generate the swirl flow that improve the combustion performance and hence the engine performance.

(Noor, et al.,2008) have developed CNG mixer and published their study as Development of a high pressure compressed natural gas mixer for a $\mathbf{1 . 5}$ liter CNG-diesel dual engine. The mixer prepares the mixture of $\mathrm{CNG}$ and Air before supplying to the cylinder or just before entering the inlet valve. This mixing ensures that stoichiometric $\mathrm{A} / \mathrm{F}$ ratio which is around 17.3 is maintained accurately. CFD analysis using COSMOS Flo Work is also carried out which uses Navier- Stokes equations assuming boundary condition for $\mathrm{CNG}$ and Air inlet pressure.

CFD optimization of venturi mixer design in bifuel gas engines by Mr. Prasanna Sutar (2010) deals with geometric parameter of mixer design in which basic three types of mixer having10,12, 16 holes at the throat is considered based on the study of isentropic compressible flow analysis. Finally optimal mixer design is selected using CFD analysis with the help of FLUENT 14.5 software package and it is 16 hole design. (Yvonne, et al., 2007) have aimed towards the study of various injection frequencies for improving the mixing quality in Computational Fluid Dynamics simulation of injection mixer for CNG engines. Initially an injection frequency $1,2,4$, 5and 7 per cycle is assumed and by simulating all of them using CFD the optimum injection frequency are chosen. Study is concluded by selecting 4injections per engine cycle which is most optimal for best mixing.

(Kadirgama, et al.,2008) have published their research work as Design and simulate mixing of compressed natural gas with air in a mixing device. This research work is dealing with design optimization of $\mathrm{CNG}$ and Air mixer to have A/F ratio chemically correct under all operating conditions. COSMOS FloWork software is used to simulate different configuration of mixer and based on that optimum design is selected. Assumptions made for initial conditions are as follows: (1) Air inlet conditions (2) CNG inlet conditions (3) Flow rate out of the mixer (CNG + Air).

(Bakar, et al.) presented on Effect of air fuel mixer design on engine performance and exhaust emission of a CNG fueled vehicles in which experiments were carried out to investigate the effect of air/fuel mixer on the engine performance and exhaust emission of a CNG fueled engine. Three types of mixers were fabricated to create the turbulent effect of an air fuel mixture. The modification is based on the mixing characteristics and turbulent coefficient. In this investigation, the CNG fueled engine is not optimized. The experiments also showed that the air fuel ratio affected the CNG engine performance. The highest air fuel ratio gives the highest pressurerise, hence the highest engine performance. Higher air fuel ratio also increased the thermal efficiency of the engine. Since CNG fuel has a higher flammability, implementation of higher air fuel ratio, in some cases even lean and ultralean burn will make a higher benefit .

Development of a compressed natural gas (CNG) mixer for a two stroke internal combustion engine presented as thesis work by (Devarajan, 2005). A mixer provides fuel suction at different engine speeds due to pressure difference at the throat. The optimization of the throat is important as a small throat will cause poor performance at high speeds while a large throat will reduce fuel suction. The smaller throat size creates higher velocity and lower pressure. The mixer was designed for a two stroke engine air flow. Computer aided design(CAD) and computational fluid dynamic (CFD)software were used as a tool for the design. The design is optimized for inlet and outlet angles, number and size of the hole at the throat circumference and also the throat size. Conclusion of this work was made by designing CNG mixer having dimensions: Length $=60 \mathrm{~mm}$, Inlet and Outlet angles $=60^{\circ}$, Location and number of holes $=24$ $\mathrm{mm}$ from inlet and 12, Size of hole and Throat $=2 \mathrm{~mm}$ and $19 \mathrm{~mm}$, Maximum Pressure drop $=4400 \mathrm{~Pa}$.

(Ramasamy et al., 2010) have published research paper under title Design of compressed natural gas mixer using computational fluid dynamics in which to reduce the time to design computational fluid dynamics (CFD) is used to get the desired flow condition inside the mixer. Calculation is done for the initial sizing of the throat of the mixer and later is simulated to obtain the best flow characteristics. Different preliminary design is to get the best shape of 
the mixer. With the help of CFD the best shape is taken for fabrication. The initial calculation for sizing is based on the stoichiometry of the fuel and general fluid dynamic equations. Conclusion was made that the parameters pressure drop, mass fraction and velocity were found within satisfactory limit somodel can further be validated experimentally.

Bhaskor J. Bora et al have published research work as Investigation on the flow behavior of a venturi type gas mixer designed for dual fuel diesel engines. In this paper, the flow behavior in a newly designed gas mixer has been investigated with the help of computational fluid dynamics based software. The contours of pressure, turbulence intensity, velocity and mass fraction of $\mathrm{CH} 4$ obtained are discussed, and compared across an existing design. In this study comparison between existing $\mathrm{T}$-junction design and proposed venturi design is made. It is seen that the venturi type design provides a higher pressure drop at the throat region and ensures a better suction of biogas which ultimately boosts the mixing. This design further provides the flow to be converged at the throat, and thereafter, scatters in the diverging section covering a larger volume with a uniform concentration of $\mathrm{CH} 4$. Thus, the venturi type gas mixer seems to provide far better mixing of fuel biogas and air than the existing $\mathrm{T}$ junction gas mixers.

\section{Summary}

From literature review study following content is summarized which forms the rigid basis to guide for any future work in this area: (1) Factors which need to be optimized for accurate mixing and better performance: Kinetic Energy of charge, inlet valve cross section area and pressure of CNG and air before mixing. (2) Swirl intensity is depending upon factors stated as: Number of intake ports, inlet valve shrouding, amount of valve lift and CNG mixer design. (3) Parameters affecting mixer design is concluded and they are: Inlet and outlet diameter, throat diameter, inlet and outlet angle, size and number of holes at throat section and CNG inlet tube size. (4) Swirl tendency has direct influence on following: Reducing fuel consumption, improving volumetric efficiency and improvement in power as well as torque for specific range of speed.

Hence swirl tendency is improved via Mixer design optimization and thus the engine performance enhancement is expected.

\section{Conclusion}

The major objective of this research of literature is to obtain clear view about the problems that have to be faced using CNG as fuel in SI Engine in terms of performance and to identify parameters that may improve CNG engine performance. Those are,

(1) Compression ratio

(2) Spark intensity and timing

(3) Exhaust Gas Recirculation (EGR)

(4) Swirling motion of charge (CNG + Air mixture)
Out of which the parameters Swirling motion of charge is the topic that is still not that much exposed as far as other research work is concern and so has ample opportunity to work with. Moreover, to develop higher swirl intensities the design of mixer which mixes CNG and air must be focused. The important design parameters concluded for mixer are throat diameter, number of holes at throat section and their diameter, inlet-outlet angle etc. which can be varied to obtain different design. Fluid flow analysis of each design is carried out in different studies and the same can be used as references to select optimized design based on pressure and velocity distribution. Still further work is open to correlate this optimized design in terms of engine output performance via enhancement is swirl tendency. Thus performance of SI Engine fueled with CNG can somewhat nearer to SI Engine fueled with petrol.

\section{References}

Alternative Fuels by S. S. Thipse, JAICO Publication.

Basic Statistics of Indian Petroleum and Natural Gas 2008-09, Ministry of Petroleum and Natural Gas; Study on Common Pool Price Mechanism for natural gas in the country; Eleventh Five Year Plan, Planning Commission and Report of the Working Group on Petroleum and Natural gas sector for eleventh Plan, 2007-12.

Munde Gopal G., Dr. Dalu Rajendra S., 2012, Compressed Natural Gas as an Alternative Fuel for Spark Ignition Engine: A Review, International Journal of Engineering and Innovative Technology (IJEIT) Volume 2, Issue 6.

Alternative Fuel Systems Inc. (Web Source-http:// www.afsglobal.com), FAQ Section.

Semin and Rosli Abu Bakar (Automotive Excellent Centre, Faculty of Mechanical Engineering, University Malaysia Pahang, Locked Bag 12, 25000 Kuantan, Pahang, Malaysia), 2008, A technical review of Compressed Natural Gas as an alternative fuel for internal combustionengines, American J. Of Engineering and Applied Sciences (4): 302-311, 2008. (ISSN 1941-7020).

Bharadwaj Abhilash M , K Madhu, Seemanthini J, Vismay K G, Shivapuji Anand M \& Aravind T (Dept. Of Mechanical Engineering, Atria Institute of Technology, Bangalore and Indian Institute of Science, Bangalore), 2013, Study of swirl and tumble motion using CFD, ISSN: 2319 - 3182, Volume-2, Issue-1.

CFD Investigation of Fluid Flow and Turbulence Field Characteristics in a Four-Stroke Automotive Direct Injection Engine by Wendy Hardyono Kurniawan, Abdullah Shahrir, Kamaruzzaman Sopian, Zulkifli Mohd. Nopiah and Azhari Shamsudeen. Journal - The Institution of Engineers, Malaysia (Vol. 69, No.1, March 2008).

Ramadan Bassem (Kettering University, 1700 University Ave, Flint, MI 48504, United States) presented on A study of swirl generation in DI Engines using KIVA-3V (2009).

Timoney, David J. and Smith William J., 1996, Influence of fue injection and air motion energy sources on fuel air mixing rates in a DI Diesel combustion system, SAE Paper 960035.

Poulos, Stephen G., Heywood and John B., 1983, The effect of chamber geometry on spark ignitionengine combustion, SAE Paper 830334

Abianeh Samini O. (M.Sc. Student, Mechanical Engineering Department, Tarbiat Modares University, Tehran, Iran), 2009, Investigation of swirling and tumbling flow pattern of spark ignition engine, The Journal of Engine Research, Vol.14.

Kumar B, Sivagaminathan N and Gopalakrishnan N (Larsen and Toubro Limited, IES), Scott Morton and Paul Radavich (Mercury Marine Pvt. Ltd, India), 2007, Air flow and charge motion study of engine intake port.

Takenaka, Y., Yabe, M., Aoyagi, Y. and Shiozaki, T., 1990, Three Dimensional Computation of In-Cylinder Flow with Intake Port in DI Diesel Engine, International Symposium COMODIA 90: 425 430 . 
Kang, Kern Y., and Reitz, R.D, 1999, The effect of intake valve and alignment on swirl generation in a DI diesel engine, Experimental Thermal and Fluid Sciences, 20, 94-103.

A.K.M. Mohiuddin (Mechanical Engineering Department, Kulliyyah of Engineering, International Islamic University Malaysia (IIUM), Jalan Gombak, 53100 and Kuala Lumpur, Malaysia), 2011, Investigation of the swirl effect on engine using designed swir adapter, IIUM Engineering Journal, Special Issue, Mechanical Engineering

Kyung-H L, Kisung K., 2001, Influence of initial combustion in SI engine on following combustion stage and cycle-by-cycle variations in combustion process, International Journal of Automotive Technology.

Thesis work by DeHong Zhang (M.Sc., Zhejiang University, China), 1995, Turbulence swirling combustion of premixed natural gas and air for the degree of Doctor of Philosophy, The University of British Columbia, Vancouver,Canada.

Ahmedi-Befrui, B., Gosman, A.D., Lockwood, F.C., And Watkins, A.P., 1981, Multidimensional calculation of combustion in an idealized homogenous charge engine: a progress report, SAE paper 810151.

Porpatham (School of Mechanical and Building Sciences, VIT University, Vellore 632 014, India), A. Ramesh and B. Nagalingam (IC Engines Laboratory, Indian Institute of Technology Madras, Chennai 600 036, India), 2013, Effect of swirl on the performance and combustion of a biogas fueled spark ignition engine, Energy Conversion and Management 76 (2013) 463-471, Elsevier.

Sita Rama Raju AV. Experimental investigations on the performance of a lean burnspark ignited gas engine. Ph.D. thesis, I.C. Engines Lab, IIT Madras, Chennai, India; 2001.

J. N. Kim and S. D. SA (Graduate School of Mechanical Engineering, Korea University, Seoul 136-701, Korea), H. Y. Kim and S. S. Yoon (Department of Mechanical Engineering, Korea University, Seoul 136-701, Korea), 2007, Effect of intake valve swirl on fuel-gas mixing and subsequent combustion in a CAI engine, International Journal of Automotive Technology, Vol. 9, No. 6, pp. 649-657.

Cao, Li., Zhao, H., Jiang, X. and Kalian, N. (2006). Investigation into the effect of injection timing on stoichiometric and lean CAI operations in a 4-stroke GDI engine. SAE Paper No. 2006-01-0417.

Mattarelli, E., Borghi, M., Balestrazzi, D. andFontanesi, S. (2004). The influence of swirl control strategies on the intake flow in four valve HSDI diesel engines. SAE Paper No. 2004-01-0112.

Henrik W. R. Dembinski and Hans-Erik Angstrom (Scania CV AB, Royal Institute of Technology Stockholm), 2011, Optical study of swirl during combustion in a CI engine with different injection pressures and swirl ratios compared with calculations, Copyright (C) 2011 SAE International, 2012-01-0682.

Thesis work by Devender Kumar, 2012, Studies on improvement of intake manifold for compressed natural gas engine for the degree of Masters of Engineering in thermal engineering, Thapar University (Established under section 3 of UGC Act, 1956) Patiala 147001, India.

Bakar Rosli Abu, Aziz Azhar Abdul and Sera Mardani Ali , 2002, Effect of air fuel mixer design on engine performance and exhaust emission of a CNG fueled vehicles, 2nd World Engineering Congress, Sarawak, Malaysia.

Safari M, Nasiritosi A and Ghamari M, 2003, Intake manifold optimization by using 3D-CFD analysis, SAE paper, pp. 32-73.

Dr. Rosli Abu Bakar, Mr. Mardani Ali Sera and Mr. Sin Kwan Leong (University Technology Malaysia), 2002, Design and development of a new CNG (Compressed Natural Gas) engine.

Kato, K., Igarashi, K., Masuda, M., Otsubo, K., Yasuda, A., Takeda, K. and Sato, T., 1999, Development of engine for natural gas vehicle,Society of Automotive Engineers SAE Paper 1999- 010574.

Kern, Y. K., and Reitz, R.D., 1999, The effect of intake valve alignment on swirl generation in a DI diesel engine, Experimental Thermal and Fluid Science 20 (1999) 94-103.

M.M. Noor, Kumaran Kadirgama and Ramasamy Devarajan (University Malaysia Pahang, Malasia), T.F. Yusaf (University of Southern Queensland, 487/521-535 West St, Darling Heights QLD 4350, Australia), 2008, Development of a high pressure Compressed Natural Gas mixer for a 1.5 liter CNG-diesel dual engine, National Conference on Design and Concurrent Engineering.
R.Devarajan et al, 2008, Comparative evaluation of a two stroke compressed natural gas mixer design using simulation and experimental techniques, International Conference on Association of Science and Technology for Development, Power And Energy Systems, Langkawi., 359-362.

Mr. Prasanna Sutar (PG Scholar, M.Tech I.C. Engines, Vel Tech University Chennai - ARAI Academy, Pune), 2010, CFD optimization of venturi mixer design in bi-fuel gas engines, IRFInternational Conference Organized by Institute of Research and Journals in association with: COE, Bharti Vidyapeeth, Deemed University, Pune.

$\mathrm{Xu}$ B. Y. and Furuyama M., 1997, Visualization of natural gas-air mixing flow in the mixer of a CNG vehicle, Technical Notes, JSAE Review, 185782.

Chang Yvonne S. H., Yaacob Z. and Mohsin R. (Proceedings of the World Congress on Engineering and Computer Science, San Francisco, USA), 2007, Computational Fluid Dynamics simulation of injection mixer for CNG engines, Proceedings of the World Congress on Engineering and Computer Science 2007, WCECS 2007, San Francisco, USA.

Papageorgakis, G. and Assanis, D. N., 1998, Optimizing Gaseous FuelAir Mixing in Direct Injection Engines Using an RNG Based k- $\varepsilon$ Model, SAE Technical Paper Series, SAE 980135.

Ferrell, G. B., Aoki, K. and Lilley, D. G., 1985, Flow Visualization of Lateral Jet Injection into Swirling Crossflow, AIAA 23rd Aerospace Sciences Meeting. January 14-17. Nevada: American Institute of Aeronautics and Astronautics.

Kadirgama K., Noor M. M., Rahim A.R.N.A., Devarajan R., Rejab M.R.M and Zuki N.M. (Malaysian Technical Universities Conference on Engineering and Technology, Putra Palace, Perlis, Malaysia), 2008 Design and simulate mixing of Compressed Natural Gas with air in a mixing device, Proceedings of MUCET2008, Malaysian Technical Universities Conference on Engineeringand Technology, Putra Palace, Perlis, Malaysia. (ISBN 978-983-42358-4-0).

Jalal Mengat, Muhammad Adlan Abdullah, Mohammad Ghadaffi Mohd Noh, Faridon Idris, Petornas Research and Scientific Services Sdn. Bhd. Malaysia. Evaluation of Bi-Fuel NGV Vehicle for Utilization of Natural Gas as the Alternative Fuel, 1996

Thesis work by Ramasamy D. A/L, 2005, Development of a compressed natural gas (CNG) mixer for a two stroke internal combustion engine for the degree of Master of Engineering (Mechanical), University Technology, Malaysia.

Sera M., Bakar R. A. and Leong S. K., 2003, CNG engine performance improvement strategy through advanced intake system, University Technology, Malaysia, JSAE 20030229, SAE 2001-011937, Japan.

Ramasamy D., Mahendran S., Kadirgama K. and Noor M .M. (Faculty of Mechanical Engineering, University Malaysia, 26300 UMP Kuantan, Pahang, Malaysia), 2010, Design of compressed natural gas mixer using computational fluid dynamics, National Conference in

Mechanical Engineering research and postgraduate students (1st NCMER 2010)

Wang X. and Zhang Y., 1991, Development of a Critical Air Flow Venturi for Air Sampling, Department of Agricultural Engineering, University of Illinois at Urbana- Champaign, USA.

Bhaskor J. Bora and Biplab K. Debnath (PhD Student), Saha U. K. (Professor), Sahoo N. (Associate Professor) from Department of Mechanical Engineering, Indian Institute of Technology Guwahati, Guwahati 781039, India and Nikhil Gupta (B.Tech Student, Department of Mechanical Engineering, Sardar Vallabhbhai National Institute of Technology, Surat ,Gujarat - 395007, India), 2013, Investigation on the flow behavior of a venturi type gas mixer designed for dual fuel diesel engines, International Journal of Emerging Technology and Advanced Engineering Volume 3, Special Issue 3: ICERTSD 2013, pages 202-209.

Hussain, S. M., Kumar, B. S., Reddy and K. V. K., 2012, CFD Analysis of Combustion and Emissions To Study the Effect of Compression Ratio and Biogas Substitution in A Diesel Engine with Experimental Verification, International Journal of Engineering Science and Technology, (2): $473-492$. 